\title{
Battle of Sharing Economy : The Contingent Effects of Ride-Sharing on Taxi Industry
}

\author{
Yunseok Lee \\ KAIST College of Business \\ yunseok.lee@kaist.ac.kr
}

\author{
Jiyong Park \\ KAIST College of Business \\ jiyong.park@kaist.ac.kr
}

\author{
Byungtae Lee \\ KAIST College of Business \\ btlee@kaist.ac.kr
}

\begin{abstract}
With the rapid growth of sharing economy, there has been a bitter controversy on the disruptive nature of sharing economy to threaten traditional industry. This study examines the impact of ride-sharing services, which is one of the most successful business models in sharing economy, on taxi industry. Using comprehensive data on Uber and taxi transactions in New York City from April to September 2014, we find that ride-sharing is negatively associated with the demand for taxis. Interestingly, this effect is contingent upon market- and customer-segments. The negative effect of Uber on taxis is mostly driven in Manhattan and high-income areas, where most taxis are concentrated. Furthermore, our analyses reveal that ride-sharing services take more demand of taxi customers who pay by cash and who are price-sensitive, by providing relative advantages of ride-sharing platforms. In addition, taxi customers in groups appear to more switch to ride-sharing services. Relevant implications for both research and practice are discussed.
\end{abstract}

\section{Introduction}

Sharing economy has received notable attention in the last few years, and information technology (IT)enabled sharing platforms have rapidly expanded. According to the research of $\mathrm{PwC}$ [37], sharing economy grows more than $30 \%$ annually, and it is expected that the scale of sharing economy would reach the scale of traditional economy sectors in 2025. By virtue of its dominance in the global market, ridesharing has recently come to the forefront of the debate on sharing economy. Uber Technologies Inc. ("Uber" hereafter), the world's largest ride-sharing platform, rapidly expanded at an unprecedented scale.

With the rapid growth of sharing economy, there has been a growing debate on the disruptive nature of the sharing economy to threaten traditional industry [13].
The disruptive force of the sharing economy has raised challenges for incumbent industries as well as policy makers. Zervas et al. [50] suggest that the $10 \%$ increase of Airbnb listing leads to the $0.39 \%$ decrease in hotel revenue. In particular, as one of the most successful business models in sharing economy, the questions about the societal impacts of ride-sharing on taxi industry are part of a larger debate over regulation of sharing economy [33].

Despite their enormous societal impacts, there is surprisingly little systematic evidence on the relationship between ride-sharing and taxi industry. Although many detractors and regulators in major cities have raised concerns on cannibalization of taxi demand by the ride-sharing services, the narrative about the competition between ride-sharing services and taxis is largely anecdotal. Thus, we have limited understanding of how the increased usages of ride-sharing platforms affect the demand for taxis. To bridge this gap, this study aims at answering the research questions: (1) Whether and how much does ride-sharing impact the demand for taxis? (2) If so, which customers does ridesharing take from the taxi industry?

It is noteworthy that the effects of IT-enabled new services and business models on conventional ones have been widely covered in the information systems (IS) literature, though these effects are not always negative. For instance, Ghose et al. [21] repute a widespread concern that IT-enabled used-product market will significantly cannibalize new product sales, as mentioning that "this proposition, while theoretically possible, is based on speculation as opposed to empirical evidence.” Danaher et al. [14] also suggest that digital distribution channels are poor substitutes for physical sales. Hence, quantifying the impact of ride-sharing on taxi industry is important not only for practitioners and policy makers, but also for researchers.

Figure 1 shows the trends in Uber and taxi transactions in NYC over the period April to September, 2014. The usage of Uber has doubled during 6 months, whereas transactions of taxis have decreased by approximately 5\%. However, as neither controlling for important region- and time-specific heterogeneity nor 
reflecting an appropriate econometric model for the interplay between Uber and taxis, these patterns of Uber and taxis leave it ambiguous whether the demand change for taxis can be attributable to the growth of ridesharing.

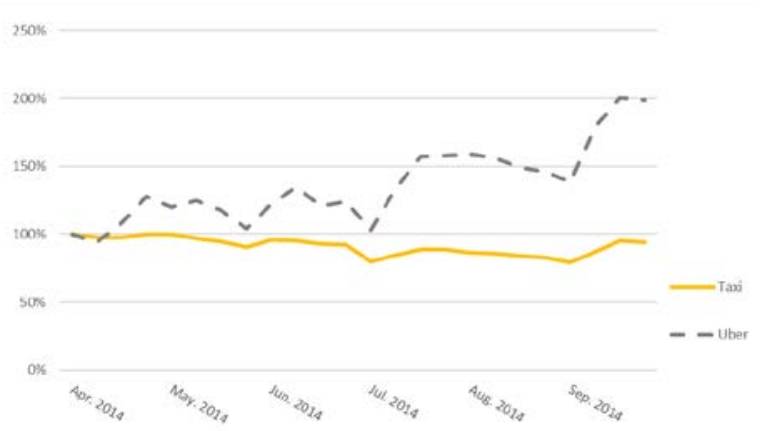

Figure 1. Trends in Uber and taxi pickups in NYC

To examine the impact of ride-sharing on taxi industry, we use fine-grained datasets on Uber and taxi pickup transactions in New York City (NYC) for the period April to September 2014 with over 800,000 zip code-hour level observations. As our identification strategy, we employ three-stage least squares (3SLS) regression model to estimate a simultaneous interaction between taxi and Uber, enabling us to address a potential simultaneous bias. Further, we explore the contingent effects depending on market- and customersegments to provide deeper understanding of how ridesharing services compete with taxis.

Our findings demonstrate that Uber and taxi are directly competing with each other in NYC, as consistent with a conventional view. The $10 \%$ increase in the number of Uber pickups leads to the $0.12 \%$ decrease in the number of overall taxi pickups in NYC, at all reasonable levels of significance. What is most striking, though, is that the effect of Uber on taxi demand is contingent upon market- and customersegments. The negative effect of Uber on taxis is mainly driven in Manhattan and high-income areas, where most taxis are concentrated. Furthermore, our analyses reveal that ride-sharing services take more demand of taxi customers who pay by cash and who are price-sensitive, by providing relative advantages of ride-sharing platforms. In addition, taxi customers in groups appear to more switch to ride-sharing services.

This paper offers the following key contributions. First, this is the first study to quantify and provide systematic evidence on the impact of ride-sharing on taxi market, using a large-scale dataset and an appropriate econometric model. This study extends the evidence of the sharing economy's disruptive nature into the ride-sharing, though we document distinct effects of Uber on taxi demand by region and income level. Notably, given that ride-sharing has grown more rapidly in outer boroughs and low-income areas (see Figure 3), our findings highlight the critical role of ridesharing in expanding transportation options for the markets underserved by taxis, while not cannibalizing the taxi demand.

Second, we differentiate various types of taxi customers and find that the Uber's impact is different depending on customer-segments. In practical terms, this study provides managerial implications that ridesharing companies need a target marketing strategy to effectively capture customer demands depending on customer-segments and spatiotemporal characteristics. In addition, our findings are also encouraging for taxi industry because all markets are not cannibalized by ride-sharing services.

\section{Literature Review}

In the IS literature, a large stream of studies covers the competition between IT-enabled new services and conventional (offline) ones. For instance, prior literature has paid attention to whether digital goods and digitally distributed contents cannibalize the demand for physical goods [14, 43]. In addition, many studies investigate how the emergence of electronic commerce can affect brick-and-mortar stores [4, 7, 8]. In the literature, ITenabled services and business models are not always substitutes for conventional ones, rather their effects have been reported as insignificant or even positive, expanding the market without cannibalization for conventional services [14, 21].

In line with this literature, there is a bitter controversy over the disruptive nature of IT-enabled sharing economy to threaten traditional industry which is mainly based on offline businesses. Zervas et al. [50] provide the first systematic evidence of how sharing economy competes with traditional industry in the case of Airbnb and hotel industry. Using a city-month level difference-in-difference setting, they empirically investigate the impact of Airbnb's entry on hotel industry, arguing that the $10 \%$ increase of Airbnb listing affect the $0.39 \%$ decrease in hotel revenue.

Surprisingly, however, there is little systematic empirical evidence on the relationship between ridesharing and taxi industry, which is one of the most successful business models in sharing economy. In the absence of rigorous empirical evidence, there are a number of mixed opinions in the industry about the effect of ride-sharing on taxi demand. FiveThirtyEight, an Internet media, compares the frequency of monthly taxi pickups in NYC between 2014 and 2015, arguing that Uber is taking millions of Manhattan rides away from taxis [18]. The Economist [45] also suggests that the average price for NYC's medallions has fallen from 
one million dollars in 2014 to 0.7 million dollars in 2015. However, they claim that "attributing these woes to Uber is difficult," given that Uber is not taxis' only new source of competition because the NYC introduced boro taxis and bicycle-sharing systems in 2013. In addition, not all Uber passengers would otherwise have hopped in a cab. Rayle et al. [39] suggest that $39 \%$ of their survey participants said that they would have used a taxi if ridesharing services were not available.

However, previous studies have several notable limitations to be addressed in this study. First, these studies mostly rely on aggregate level data, such as city and month level. These results should be suffered from aggregation problems and confounding effects. Especially, the spatial-temporal variation of taxi and Uber is more evident than other markets such as accommodation. To the extent that there may be variation in the effects depending on region and time, understating these spatiotemporal effects and isolating the magnitude of them are important in assessing the ride-sharing effects. Thus, our granular level data on trip record for Uber and taxis in NYC allow us to exploit spatiotemporal variations of Uber and taxi transactions, and further investigate the distinct effects of ridesharing by region and time.

Second, assessing and quantifying the causal effects of ride-sharing on taxi demand poses an empirical challenge due to endogeneity, making identification difficult. For instance, Wallsten [48] presents the evidence of the relationship between Uber's popularity and the decline of consumer complaints per trip about taxis in NYC, possibly due to taking away taxi's customers or improving taxis' service in response to the new competition. However, the author also mentions that "the data do not make it possible to derive the magnitude of the effects of Uber." Quantifying the impact of ride-sharing on taxi industry is essential to provide implications for practitioners and policy makers, given that it has been subject to much debate among them. Hence, with granular level datasets and an appropriate econometric technique, this study attempts to quantify the impact of ride-sharing on taxi industry.

\section{Hypothesis Development}

\subsection{Competition between ride-sharing and taxi}

According to the framework of competitor analysis [9], the degree of competition is determined by market commonality and resource similarity. Given that ridesharing and taxi provide similar riding services for customers, it is reasonable to conjecture that the increased usages of ride-sharing platforms would reduce the demand for taxis.
Furthermore, the disruptive power of ride-sharing stems from the characteristics of online platforms. ITenabled platforms could dramatically lower search costs [3] and facilitate buyer-seller match, leading to a frictionless market [8]. Contrary to taxi services, ridesharing platforms facilitate to seamlessly connect customers to the nearest driver when they request a ride. Reduced search costs could allow people to hire more ride-sharing drivers. In addition, people would be more likely to use ride-sharing platforms because the ridesharing services offer a significant price reduction over traditional taxis (e.g., UberX) and are quite easy to use and useful; otherwise they would be unlikely to do [22]. We thus propose the following hypothesis to be empirically tested as a baseline:

Hypothesis 1. Ride-sharing services will be negatively associated with the demand for taxis.

\subsection{Contingent effects of market segments}

The mixed opinions of ride-sharing's impacts on taxi industry may be attributed to not only the absence of empirical evidence, but also its contingency depending on market- and customer-related factors. The inherent feature of online platforms to reduce search costs can influence the market commonality, and consequently the degree of competition between ride-sharing services and taxis. In the taxi market, search costs are substantial not only for customers as buyers, but also for drivers as sellers. Patron relies on stochastic discovery of a taxi by standing on the street. Taxi drivers get around to search for uncertain, potential customers across the city if not arranged by calls in advance. Due to high search costs, taxi drivers tend to be concentrated spatially in downtown and temporally during the daytime or rush hour, making customer's search costs higher in the taxisparse areas and time. Hence, the costs for searching taxi and ride-sharing services will be low enough to easily get both in the taxi-dense areas. Cramer and Krueger [12] find that the capacity utilization rates of taxi and Uber drivers are much more similar in NYC than in other cities. The authors suggest that the high population density of NYC supports more efficient matching of taxis and passengers through street hailing than is the case in other cities. While they do not separate out Manhattan from outer boroughs in NYC, their argument is valid only in Manhattan where most taxis are concentrated (more than 90\%).

On the other hand, contrary to taxi services, ridesharing platforms could reduce driver's search costs, as well as customers' ones, through seamless driver-rider match. Ride-sharing platforms facilitate to seamlessly connect customers to the nearest driver when they request a ride. Using a simulation approach in 
estimating a dynamic general equilibrium model of the taxi market in NYC in 2011-2012, Frechette et al. [19] argue that it was estimated to reduce the search time for taxis by 9.3 percent if assuming that drivers knew the location of the closest passengers, as the case of ridesharing platforms. Reduced drivers' search costs increases expected payoffs from driving in the suburbs of the city, leading to a broader services provision. Figure 2 highlights different geographical patterns of taxi and Uber in NYC. The study of University of California Transportation Center [39] suggests that wait times of on-demand ride services are markedly shorter and more consistent that those of taxis in San Francisco. In addition, $30 \%$ of respondents in their survey said that short wait time is the reason why they chose ride-sharing, which is the second highest.

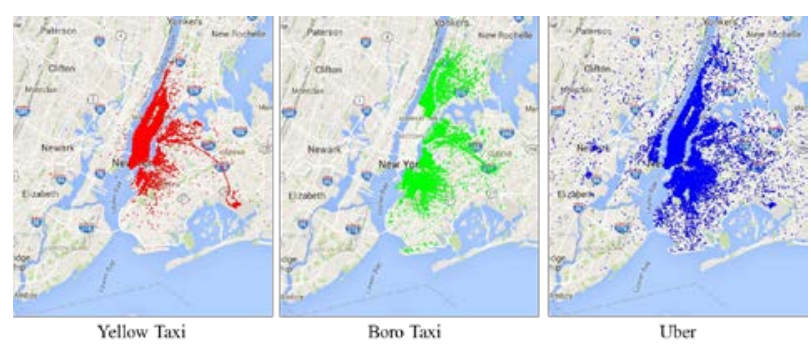

Figure 2. Uber and taxi pickups in NYC

Notes: We plot 150,000 random sample from yellow taxi pickups and 50,000 from boro taxi transactions during April 2014. Uber pickups are plotted based on 200,000 random sample during April 2014.

In the taxi-sparse areas, search costs for taxi will be higher than those for ride-sharing, making ride-sharing and Uber serve different types of customers by their marginal values for search costs. On the other hand, in the taxi-dense areas, market commonality is high and customers would treat the services of ride-sharing and taxi similarly, making the competition more intensive. According to Chen [9], the competition intensifies when market commonality is high; thus, logically, we expect that the impact of ride-sharing on taxis will be greater in the taxi-dense areas than taxi-sparse areas. This is largely consistent with Brynjolfsson et al. [7], who suggest that the competition between the Internet retailers and brick-and-mortar is much more intensive when selling famous products than niche products which consumers have a difficulty in finding in a traditional offline market.

For a goal of empirical testing, we operationalize the taxi-dense areas as Manhattan in NYC and high-income areas. As shown in Figure 2, taxi availability depends on boroughs in NYC. In addition, many studies suggest that low-income areas are underserved markets by traditional transportation such as taxi, and Uber has the potential to expand transportation option there. Using a controlled study in low-income neighborhoods in Los
Angeles, Smart et al. [42] show that an app-summoned UberX arrives in less than half the time of a telephonedispatched taxi, and more reliable with no wait time exceeding 30 minutes. Meyer [34] show that Uber are expanding transportation options in low-income areas in NYC. Therefore, we propose the following:

Hypothesis 2. The effect of ride-sharing services on taxi demand will be greater in Manhattan than outer boroughs in NYC.

Hypothesis 3. The effect of ride-sharing services on taxi demand will be greater in high-income neighborhoods than low-income neighborhoods.

\subsection{Contingent effects of customer segments}

Consumers face non-negligible costs of switching between different services for a new kind of services or technologies. In particular, access to IT or smartphones may be proffered as a barrier to widespread adoption of new ride-sharing services. Given that taxis are operating across cities before the introduction of ride-sharing services, the switching costs may play a critical role in the competition between them. The lower the switching costs for ride-sharing are, the more ride-sharing will reduce the taxi demand.

In this study, we propose two factors which could influence customers' switching behavior and subsequently the competition between new sharing economy platforms and traditional industry: relative advantage and perceived risks. Relative advantage refers to the degree to which consumers regard an alternative service to be superior to the conventional service, and it receives tremendous attentions as one of the factors to facilitate innovation adoption and diffusion [2, 40]. As consumers perceive more advantage and usefulness a service or product offers, they tend to more adopt and expect more investment in learning the service or product [15, 25]. Huang and Hsieh [24] suggest that relative advantage directly affects the switching costs and their acceptance behavior. Thus, we expect that perceived relative advantage may influence the switching behavior of taxi customers to new ride-sharing services.

The ride-sharing services have been embraced, in part, because it is cashless and its fare is automatically charged to rider's credit card after rolling up to destination. Cashless exchange systems make it easy for the users to pay seamlessly. Of many features of ITenabled ride-sharing platforms, ease of payment was the most attractive reasons to use ride-sharing (35\% of survey respondents), according to a survey of Rayle et al. [39]. Furthermore, Uber maintains its policy that "tips are not included on Uber's platforms, and that tipping is neither expected nor required” [35], making 
Uber more attractive to the price-sensitive customers who are not willing to pay large tips. As a form of price discrimination, tipping allows some customers to pay less than others for the same service, and price-sensitive customers are willing to reduce the total cost of services by leaving smaller tips [23, 32]. In this regard, we expect that taxi customers who pay by cash and price-sensitive customers who give a smaller tip percentage (i.e., percentage of total fare) will perceive higher relative advantage of ride-sharing over taxi, as there's no riffling through wallet for small bills or tips. Therefore, we propose the following:

Hypothesis 4. Ride-sharing services will reduce the demand for taxi customers paying by cash more than those paying by credit card.

Hypothesis 5. Ride-sharing services will reduce the demand for taxi customers giving a small tip percentage more than those giving a large tip percentage.

In addition, there are implicit switching costs associated with decision biases and risk aversion [10]. People who have never used, or have little used a new service feel risk toward the new service. This type of risk is originated from the uncertainties about the service, and it deters risk-averse consumers from switching to and accepting new service or technology. In the context of peer-to-peer (P2P)-based sharing economy, functional and physical risk may play a key role in the adoption of the new services because its supplier is not firms but individuals. Therefore, people who are not familiar with ride-sharing services may perceive risk for safety and uncertainty for its utility.

Decision on technology adoption is made collectively by the group through a process of communication and negotiation [41], and social influence can act as an antecedent to technology adoption [46]. There is an extensive social psychology literature addressing group versus individual decision making [26]. In particular, previous studies suggest that people made a decision in group tend to be more risktaking than people made a decision alone [44, 47]. Dion et al. [16] propose four possible explanations for making riskier decision in a group: diffusion of responsibility, persuasion, familiarization, and cultural value. That is, they share their risk with other people in the group [17]. Gardner and Steinberg [20] suggest that when in peer groups than alone, the experiment participants took more risks and focused more on the benefits than costs of risky behavior. In addition, peer influence affects an user's switching intention in social network services [49] and increases the impulsive purchasing [31].
Taken together, to the extent that the perceived risk or uncertainty acts as switching costs for ride-sharing services, group customers will be more favorable toward new technology or services, than individual consumers. Thus, we propose the following:

Hypothesis 6. Ride-sharing services will reduce the demand for taxi customers in group more than those alone.

\section{Methodology}

\subsection{Data}

In this study, we employ zip code-hour level panel data on Uber and taxi pickup transactions in NYC over the period from April to September 2014. NYC provides an ideal setting for our study because Uber has been active there since May 2011, and NYC is today one of its biggest and most controversial markets. As of 2015, Lyft provided only $7 \%$ of rides summoned over the Internet in NYC, compared with Uber's 90\% [6]. In addition, while yellow cabs still make 10 times more trips than Uber cars in the city, more Uber cars were on the road than yellow taxis in NYC in 2015 [36]. This sample period also rules out the possibility of competitors' influences (such as Lyft) because Uber was the market-dominating company in NYC before 2015.

FiveThirtyEight obtained the Uber transaction data from the from NYC Taxi and Limousine Commission (TLC) by submitting a Freedom of Information Law request. This dataset contains over 4.5 million Uber pickups in NYC from April to September 2014. Additionally, we use data on approximately 90 million taxi pickup transactions for this period from the official NYC TLC trip records. Each individual trip record contains precise location coordinates and timestamps for where and when the trip started.

Uber and taxi pickup locations are specified in their latitude and longitude to four decimal places. To convert their locations into zip code level, we match the latitude and longitude to the corresponding zip code, using a geographical information systems software. Data that returned null values or zip codes outside NYC are dropped. Our final panel dataset includes 191 zip codes, and consequently 838,872 zip code-hour observations. It is worth noting that TLC also provides information on various attributes of taxi transactions in NYC, allowing us to segment customer types. The TLC trip record dataset includes transaction information about fare, tip amount, number of passenger, and payment method.

Table 1 summarizes the variables used in our datasets. 
Table 1. Summary statistics $(N=838,872)$

\begin{tabular}{|c|c|c|c|c|c|}
\hline Variables & Mean & Std. dev & Min & Max & Description \\
\hline Uber & 5.04 & 19.11 & 0 & 434 & Number of Uber pickup transactions \\
\hline Taxi & 102.17 & 267.34 & 0 & 3,290 & Number of taxi pickup transactions \\
\hline Taxi_Large tip & 52.14 & 130.78 & 0 & 1,770 & $\begin{array}{l}\text { Number of taxi transactions whose tip percentage is above median } \\
\text { (median }=9.5 \% \text { ) }\end{array}$ \\
\hline Taxi_Small tip & 50.00 & 139.46 & 0 & 1,743 & $\begin{array}{l}\text { Number of taxi transactions whose tip percentage is below median } \\
\text { (median }=9.5 \% \text { ) }\end{array}$ \\
\hline Taxi_Group ride & 29.07 & 81.36 & 0 & 1,113 & $\begin{array}{l}\text { Number of taxi transactions whose number of passenger is two or } \\
\text { more }\end{array}$ \\
\hline Taxi_Single ride & 73.10 & 187.53 & 0 & 2,321 & Number of taxi transactions whose number of passenger is one \\
\hline Taxi_Cash & 44.07 & 111.20 & 0 & 1,603 & Number of taxi transactions whose payment method is cash \\
\hline Taxi_Card & 57.29 & 157.67 & 0 & 1,936 & Number of taxi transactions whose payment method is credit card \\
\hline
\end{tabular}

\subsection{Empirical model}

Assessing the causal relationship between Uber and taxis poses an empirical challenge due to endogeneity. There are several potential sources of endogeneity that may lead to biased estimation. Firstly, there would be omitted variables that will potentially affect the demand for both Uber and taxis. Another potential source of endogeneity could be reverse causality or simultaneity bias because taxis and Uber interplay with each other. That is, taxi may affect the demand of Uber, as well as Uber influences the demand for taxis.

To address the potential endogeneity problems, we employ 3SLS model, which combines two-stage least squares (2SLS) with seemingly unrelated regression (SUR). The 3SLS approach estimates the full system of equations where endogenous variables in an equation are used as explanatory variables in other equations. It is widely adopted when dealing with endogeneity and contemporaneous cross-equation correlation between error terms [27, 29]. In particular, this approach is recommended to model a triangular structural relationship [28], allowing us to consider the simultaneous interaction between Uber and taxis. Specifically, we estimate the system of equations:

$$
\begin{gathered}
\ln \text { Taxi }_{i t}=\beta_{11} \ln \text { Uber }_{i t}+\beta_{21} \ln \text { Taxi }_{i t-1} \\
+\beta_{31} \ln \text { Taxi }_{i t-168}+\mu_{i 1}+v_{t 1}+\varepsilon_{i t 1} \\
\ln \text { Uber }_{i t}=\beta_{12} \ln \text { Taxi }_{i t}+\beta_{22} \ln \text { Uber }_{i t-1} \\
+\beta_{32} \ln \text { Uber }_{i t-168}+\mu_{i 2}+v_{t 2}+\varepsilon_{i t 2}
\end{gathered}
$$

where $\mu_{i}$ is zip code-specific effects invariant over time, $v_{t}$ is time-specific effects common across regions, and $\varepsilon_{i t}$ is a random error in zip code $i$ in time $t$. The variables of Uber $_{i t}$ and Taxi $_{i t}$, which are the frequency of pickup transactions of Uber and taxi, are log-transformed to mitigate negative skewness of its distribution, after adding one to account for zero values. We are primarily interested in $\beta_{11}$, which represents the percentage change in taxi transactions associated with one percent increase in Uber transactions.
In addition, we include 168 hours (one week) lagged term as instrument variables. The instruments should be correlated with the endogenous regressor but uncorrelated with the dependent variable through any channel other than their effects via the endogenous regressor. Since there is much fluctuation in taxi and Uber transactions depending on day-of-week and timeof-day, we believe that the demand for transportation before a week is more appropriate instruments for the current demand.

Our model also allows for the dynamic nature of Uber and taxi pickups by including variables for lagged frequency of pickups between two successive hours. The current frequency of taxi and Uber pickups can be correlated with the past pickups in two opposite ways. On one hand, previous taxi pickups may reduce the probability of street hailing in the next hour. On the other hand, the demand for taxis and Uber can be concentrated in specific time periods, such as rush hour. In this case, the current taxi pickups will be positively correlated with the past pickup transactions. Furthermore, we can deal with time-series specific effects such as autocorrelation in the demand for taxis and Uber by including one hour lagged term of the dependent variables [1].

Unobserved local conditions such as geographical (e.g., tourist attractions), demographic (e.g., race, gender) and socioeconomic factors (e.g., income) may have heterogeneous effects on both Uber and taxi demands. To account for region-specific effects, zip code dummies are included. In addition, we also include date (183 days) and time-of-day (24 hours) dummies to control for time-specific transportation demands or unobserved factors (e.g., events).

\section{Results}

\subsection{Impact of Uber on taxi demand}


To examine whether and how the frequency of Uber transactions affects the demand for taxis, we estimate the empirical model using our full sample of 838,872 zip code-hour observations, which pools 191 zip codes in NYC over six months in 2014. Table 2 reports our estimation results of the simultaneous competition between Uber and taxis. Each column in the table corresponds to a different regression.

Table 2. Results of 3SLS estimation

\begin{tabular}{|c|c|c|c|}
\hline & $\begin{array}{l}\text { Main Effect } \\
(\mathrm{H} 1)\end{array}$ & $\begin{array}{c}\text { Borough } \\
(\mathrm{H} 2)\end{array}$ & $\begin{array}{c}\text { Income } \\
(\mathrm{H} 3)\end{array}$ \\
\hline & $(1)$ & (2) & (3) \\
\hline DV: & $\ln ($ Taxi) & $\ln ($ Taxi $)$ & $\ln ($ Taxi $)$ \\
\hline In(Uber) & $\begin{array}{c}-0.0120 \star \star \star \\
(0.0007)\end{array}$ & $\begin{array}{l}-0.0007 \\
(0.0011)\end{array}$ & $\begin{array}{c}0.0002 \\
(0.0013)\end{array}$ \\
\hline $\begin{array}{l}\text { In(Uber) } x \\
\text { Manhattan }\end{array}$ & & $\begin{array}{c}-0.0145^{\star \star \star} \\
(0.0010)\end{array}$ & \\
\hline $\begin{array}{l}\text { In(Uber) } x \\
\text { Middle-income }\end{array}$ & & & $\begin{array}{c}-0.0063^{\star \star \star} \\
(0.0013)\end{array}$ \\
\hline $\begin{array}{l}\text { In(Uber) } x \\
\text { High-income }\end{array}$ & & & $\begin{array}{c}-0.0168^{\star \star \star} \\
(0.0012)\end{array}$ \\
\hline $\ln \left(\operatorname{Taxi}_{(\mathrm{t}-1)}\right.$ & $\begin{array}{c}0.379^{\star * *} \\
(0.000959)\end{array}$ & $\begin{array}{c}0.378^{\star \star \star} \\
(0.000962)\end{array}$ & $\begin{array}{c}0.383^{\star \star \star} \\
(0.000958)\end{array}$ \\
\hline $\ln ($ Taxi) $(\mathrm{t}-168)$ & $\begin{array}{c}0.421^{\star * *} \\
(0.000958) \\
\end{array}$ & $\begin{array}{c}0.421^{\star * *} \\
(0.000958)\end{array}$ & $\begin{array}{c}0.414^{\star \star *} \\
(0.000962) \\
\end{array}$ \\
\hline DV: & In(Uber) & In(Uber) & In(Uber) \\
\hline $\ln ($ Taxi) & $\begin{array}{r}-0.0311^{\star \star *} \\
(0.0012)\end{array}$ & $\begin{array}{l}0.0074^{\star * *} \\
(0.0018)\end{array}$ & $\begin{array}{l}0.0129^{* * *} \\
(0.0022)\end{array}$ \\
\hline $\begin{array}{l}\ln (\text { Taxi }) \times \\
\text { Manhattan }\end{array}$ & & $\begin{array}{c}-0.0566^{\star \star *} \\
(0.0018)\end{array}$ & \\
\hline $\begin{array}{l}\text { In(Taxi) } \times \\
\text { Middle-income }\end{array}$ & & & $\begin{array}{c}-0.0144^{\star \star \star} \\
(0.0017)\end{array}$ \\
\hline $\begin{array}{l}\ln (\text { Taxi }) \times \\
\text { High-income }\end{array}$ & & & $\begin{array}{c}-0.0789 * \star * \\
(0.0022)\end{array}$ \\
\hline $\ln \left(\right.$ Uber) ${ }_{(\mathrm{t}-1)}$ & $\begin{array}{c}0.447^{\star \star *} \\
(0.000792)\end{array}$ & $\begin{array}{c}0.446^{\star \star \star} \\
(0.000792)\end{array}$ & $\begin{array}{c}0.445^{\star \star \star} \\
(0.000791)\end{array}$ \\
\hline In(Uber) (t-168) & $\begin{array}{c}0.478^{\star \star \star} \\
(0.000798)\end{array}$ & $\begin{array}{c}0.476^{\star \star \star} \\
(0.000799)\end{array}$ & $\begin{array}{c}0.477^{\star \star \star} \\
(0.000800)\end{array}$ \\
\hline
\end{tabular}

Notes: Standard errors are in parentheses; Region and time fixed effects are included; The baselines are outer boroughs in NYC

(Column 2) and low-income areas (Column 3), respectively. * $p<0.05$, ** $p<0.01,{ }^{* \star *} p<0.001$

Column 1 shows that Uber and taxis compete with each other by cannibalizing the other demand. The impact of Uber on overall taxi market is significantly negative, and the $10 \%$ increase in Uber pickups leads to the $0.12 \%$ decrease in overall taxi pickups, accepting the Hypothesis 1 . On the other hand, the Uber pickups decrease by $0.31 \%$ as the taxi pickups increase by $10 \%$.
To explore the contingent effects upon marketsegments, we extend the baseline model by including interaction terms between focal independent variables (e.g., $\ln$ Uber $_{i t}$ ) and dummy variables of borough and income level. We obtain data about average household income for each zip code from U.S. Census Bureau. We code a binary variable, Manhattan, as 1 if the zip code areas belong to that borough. In addition, we categorize zip code areas into three groups based on income distribution in NYC; Middle income is defined as zip code areas which reside between the 25th $(\$ 60,564)$ and 75th $(\$ 99,142)$ percentile of household income; and the remaining areas with higher and lower income are assigned into Highincome and Low income, respectively. Note that the baselines are outer boroughs in NYC and low-income areas, respectively.

Similarly to main terms, the interaction terms may be endogenous. For instance, the Uber transactions are endogenous in both Manhattan and outer boroughs in NYC, thus we need to address the endegeneity of interaction term. In the prior literature [5, 29], it is widely accepted to instrument interactions of endogenous variables with interactions with instruments. Following this approach, instead of using the interaction terms that may be endogenous, we reestimate the model by including the interaction terms with instruments.

Columns 2 and 3 in Table 2 provide intriguing findings that the Uber's impacts on taxi demand are contingent upon borough and income level. In Column 2 , the impact of Uber on taxis in Manhattan is significant, but not in outer boroughs, supporting the Hypothesis 2. In Manhattan, the $10 \%$ increase in Uber pickups leads to the $0.14 \%$ decrease in taxi pickups. On the other hand, the impact of Uber on taxi market in low-income areas is insignificant and negligible (Column 3), whereas its impact is negatively significant in middle- and highincome areas, supporting the Hypothesis 3 . When the Uber pickups increase by $10 \%$, taxi pickups decrease by $0.17 \%$ in higher-income areas.

\subsection{Customer-segment analysis}

In order to investigate whether the effects of Uber vary depending on the characteristics of taxi customers, we split the taxi transactions based on its attributes: tip percentage, group ride, and payment method (see Table 1 for summary statistics). Specifically, all taxi transactions whose ratio of tip to total fare (tip percentage) is above median are divided into large tip segment, or else into small tip segment. Also, all taxi transactions whose number of passenger, reported by drivers, is two or more are classified into group-ride segment, whose number of passenger is one is classified into single-ride segment. Cash and credit card segments are classified by payment for each taxi transactions. 
Table 3. Results of customer-segment analysis

\begin{tabular}{|c|c|c|c|c|c|c|}
\hline \multirow[b]{3}{*}{ DV: } & \multicolumn{2}{|c|}{ Cash vs. Credit Card (H4) } & \multicolumn{2}{|c|}{ Small Tip vs. Large Tip (H5) } & \multicolumn{2}{|c|}{ Group vs. Single (H6) } \\
\hline & (1) & (2) & (3) & (4) & (5) & (6) \\
\hline & In(Taxi_Cash) & In(Taxi_Card) & $\begin{array}{l}\text { In(Taxi_ } \\
\text { Small tip) }\end{array}$ & $\begin{array}{c}\text { In(Taxi_ } \\
\text { Large tip) }\end{array}$ & $\begin{array}{c}\text { In(Taxi_ } \\
\text { Group ride) }\end{array}$ & $\begin{array}{c}\text { In(Taxi_ } \\
\text { Single ride) }\end{array}$ \\
\hline In(Uber) & $\begin{array}{c}-0.0217^{\star * *} \\
(0.0007)\end{array}$ & $\begin{array}{c}-0.0164^{* * *} \\
(0.0007)\end{array}$ & $\begin{array}{c}-0.0187^{\star \star \star} \\
(0.0007)\end{array}$ & $\begin{array}{c}-0.0168^{\star \star \star} \\
(0.0007)\end{array}$ & $\begin{array}{c}-0.0296^{\star \star \star} \\
(0.0007)\end{array}$ & $\begin{array}{c}-0.0117^{* * *} \\
(0.0007)\end{array}$ \\
\hline $\ln ($ Taxi) $(t-1)$ & $\begin{array}{c}0.362^{\star \star *} \\
(0.000980)\end{array}$ & $\begin{array}{c}0.368^{\star * \star} \\
(0.000967)\end{array}$ & $\begin{array}{c}0.362^{\star \star \star} \\
(0.000978)\end{array}$ & $\begin{array}{c}0.372^{\star \star \star} \\
(0.000961)\end{array}$ & $\begin{array}{c}0.363^{\star \star *} \\
(0.000979)\end{array}$ & $\begin{array}{c}0.372^{\star \star *} \\
(0.000967)\end{array}$ \\
\hline $\ln \left(\right.$ Taxi) ${ }_{(t-168)}$ & $\begin{array}{c}0.407^{\star \star *} \\
(0.000979)\end{array}$ & $\begin{array}{c}0.417^{\star \star *} \\
(0.000967) \\
\end{array}$ & $\begin{array}{c}0.410^{\star \star \star} \\
(0.000977) \\
\end{array}$ & $\begin{array}{c}0.424^{\star * *} \\
(0.000960)\end{array}$ & $\begin{array}{c}0.406^{\star \star *} \\
(0.000980)\end{array}$ & $\begin{array}{c}0.415^{\star \star *} \\
(0.000965) \\
\end{array}$ \\
\hline DV: & In(Uber) & In(Uber) & In(Uber) & In(Uber) & In(Uber) & In(Uber) \\
\hline $\begin{array}{l}\text { In(Taxi)_each } \\
\text { subsample }\end{array}$ & $\begin{array}{c}-0.0363^{\star \star \star} \\
(0.0013)\end{array}$ & $\begin{array}{c}-0.0376^{\star \star \star} \\
(0.0013)\end{array}$ & $\begin{array}{c}-0.0346^{\star \star \star} \\
(0.0013)\end{array}$ & $\begin{array}{c}-0.0392^{\star \star \star} \\
(0.0013)\end{array}$ & $\begin{array}{c}-0.0371^{\star \star \star} \\
(0.0013)\end{array}$ & $\begin{array}{c}-0.0351^{* * *} \\
(0.0013)\end{array}$ \\
\hline $\ln (\text { Uber })_{(t-1)}$ & $\begin{array}{c}0.446^{\star \star *} \\
(0.000792)\end{array}$ & $\begin{array}{c}0.446^{\star \star \star} \\
(0.000792)\end{array}$ & $\begin{array}{c}0.446^{\star \star \star} \\
(0.000792)\end{array}$ & $\begin{array}{c}0.446^{\star * *} \\
(0.000792)\end{array}$ & $\begin{array}{c}0.445^{\star \star *} \\
(0.000794)\end{array}$ & $\begin{array}{c}0.447^{\star * \star} \\
(0.000791)\end{array}$ \\
\hline In(Uber) $(\mathrm{t}-168)$ & $\begin{array}{c}0.477^{\star \star *} \\
(0.000800)\end{array}$ & $\begin{array}{c}0.477^{\star * \star} \\
(0.000799)\end{array}$ & $\begin{array}{c}0.477^{\star \star \star} \\
(0.000799)\end{array}$ & $\begin{array}{c}0.477^{\star \star \star} \\
(0.000799)\end{array}$ & $\begin{array}{c}0.477^{\star \star *} \\
(0.000801)\end{array}$ & $\begin{array}{c}0.477^{\star * *} \\
(0.000799)\end{array}$ \\
\hline
\end{tabular}

We estimate the contingent effects of customersegment by regressing different transactions of taxi, separately, on Uber transactions. Table 3 reports our estimation results for the impacts of Uber on each customer segment. As shown in Columns 1 and 2, Uber seems to take more the demand of taxi customers who pay by cash than credit card, accepting Hypothesis 4 . The $10 \%$ increase of Uber transactions causes the $0.22 \%$ and $0.16 \%$ decrease in taxi transactions whose payment method is cash and credit card, respectively, implying that the cashless payment of Uber is perceived as an important relative advantage over taxis. In Columns 3 and 4, the negative impact of Uber on the taxi transactions with a small tip is significantly larger than those who pay a large tip ( $\mathrm{p}<0.05)$, as consistent with the Hypothesis 5. The $10 \%$ increase of Uber transactions leads to the $0.19 \%$ and $0.17 \%$ decrease in taxi pickup transactions with a large and small tip percentage, respectively. Thus, these results imply that ride-sharing services take more the demand of taxi customers who are more price-sensitive, due to Uber's no-tipping policy.

In Columns 5 and 6, we can accept the Hypothesis 7, as the demand elasticity of Uber for group taxi rides is more than twice as large as for single taxi rides. The $10 \%$ increase of Uber transactions is associated with the $0.30 \%$ and $0.12 \%$ decrease in group taxi ride and single taxi ride, respectively. The large difference between group and single taxi ride implies that perceived risk may play a critical role in customers' attitude to new IT-enabled services and P2P-based sharing economy.

\section{Discussion and Conclusions}

This study provides intriguing and encouraging findings of societal benefits of ride-sharing. Our findings demonstrated that the negative effect of Uber on taxi demand seems to be mainly driven by Manhattan and high-income areas, where most taxis are concentrated, although the Uber's impact is insignificant in the outskirts (outer boroughs) and lowincome areas. The suburbs and low-income areas have been underserved by public transits and street-hail transportations [11, 34], possibly undermining the quality of life and social welfare. Figure 3 shows the trends of Uber transactions by income level during the sample period. The growth of Uber pickups is more evident in middle- and low-income areas, and the percentage of Uber transactions there has increased over time, contrary to taxis. Thus, our findings highlight that ride-sharing services can be effective in expanding transportation options in these underserved markets, without cannibalizing the demand for taxis there.

This paper offers important contributions and implications to literature and practice. First, this study can contribute to the nascent literature on societal impacts of sharing economy. The availability of ridesharing can reduce the likelihood of alcohol-related motor vehicle fatalities [22] and also can reduce traffic congestion and excess fuel consumption [30]. Our work extends the evidence of the societal impacts of sharing economy by documenting the relationship between ridesharing and the incumbent taxi industry. 


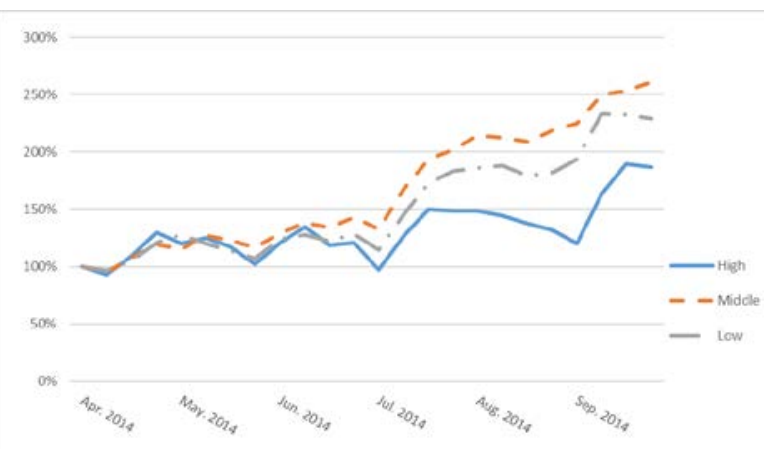

Figure 3. Trends in Uber pickups by income level

Second, we documented the distinct impacts of Uber on taxi demand by region and income level. Rawls [38] proposes the social welfare measure based on the welfare level for the least well-off people in society, referred to as Rawlsian utility function. From the Rawls' perspective, increasing social welfare of the lowerincome people can lead to the improve of overall social welfare. Thus, our study illustrates a new channel through which ride-sharing platforms improve social welfare beyond economic gains by expanding transportation options mostly in low-income areas without cannibalizing the taxi demand. This may reshape the ongoing dialogues on the sharing economy and inform democratic debate on ride-sharing and sharing economy that have been subject to much debate among researchers and policy makers. These differing impacts of ride-sharing by regions can provide a possible way for policy makers to reconcile the conflicting opinions from the traditional industry, consumers, and sharing economy players.

Third, we attempted to differentiate types of taxi customers, providing managerial implications for sharing platform companies as well as traditional industry. Our findings imply that ride-sharing companies may need a target marketing strategy to effectively capture customer demands depending on customers' characteristics. In addition, the results are encouraging for taxi industry because all markets are not cannibalized by the new competition with ride-sharing.

This study is also not without limitations. First, our findings may be limited by the sample period in 2014, a relatively early stage of Uber growth in NYC. Given that the impacts of Uber may be depending on its growth phase, one should be cautious in generalizing our results to other periods or other cities which may experience different stages of ride-sharing adoption.

In addition, our fine-grained analyses can effectively capture the short-term direct cannibalizing effects of ride-sharing services, though it may not capture the long-term impacts of ride-sharing on taxi industry, such as its structural change caused by Uber's flexible labor supply model [12]. The total impacts of ride-sharing, including short-term and long-term effects, on taxi industry might be broader and greater than our estimates.

Second, since NYC is one of the world's largest cities and hosts many ride-sharing drivers, the effects of ride-sharing there might differ from those in other cities. In addition, different regulations for ride-sharing might affect their competitive relationship. Future studies could extend our empirical findings to other contexts, such as other cities and other countries.

\section{References}

[1] Archak, N., Ghose, A., and Ipeirotis, P.G. Deriving the Pricing Power of Product Features by Mining Consumer Reviews. Management Science 57, 8 (2011), 1485-1509. [2] Arts, J.W.C., Frambach, R.T., and Bijmolt, T.H.A. Generalizations on consumer innovation adoption: A metaanalysis on drivers of intention and behavior. International Journal of Research in Marketing 28, 2 (2011), 134-144. [3] Bakos, Y. Reducing Search Costs: Implications for Electronic Marketplaces. Management Science 43, 12 (1997), 1676-1692.

[4] Bakos, Y., Lucas, H.C., Oh, W., Simon, G., Viswanathan, S., and Weber, B.W. The Impact of E-Commerce on Competition in the Retail Brokerage Industry. Information Systems Research 16, 4 (2005), 352-371.

[5] Bartik, T.J. The Estimation of Demand Parameters in Hedonic Price Models. Journal of Political Economy 95, 1 (1987), 81.

[6] Bradley, R. Lyft's Search for a New Mode of Transport. MIT Technology Review, 2015.

[7] Brynjolfsson, E., Hu, Y., and Rahman, M.S. Battle of the Retail Channels: How Product Selection and Geography

Drive Cross-Channel Competition. Management Science 55, 11 (2009), 1755-1765.

[8] Brynjolfsson, E. and Smith, M.D. Frictionless Commerce? A Comparison of Internet and Conventional Retailers. Management Science 46, 4 (2000), 563-585.

[9] Chen, M.-J. Competitor Analysis and Interfirm Rivallry: Toward a Theoretical Integration. Academy of Management Review 21, 1 (1996), 100-134.

[10] Chen, P.Y. and Hitt, L.M. Measuring Switching Costs and the Determinants of Customer Retention in InternetEnabled Businesses: A Study of the Online Brokerage Industry. Information Systems Research 13, 3 (2002), 255274.

[11] Cooper, J., Mundy, R., and Nelson, J. Taxi! Urban Economies and the Social and Transport Impacts of the Taxicab. Ashgate Publishing, Farnham, 2010.

[12] Cramer, J. and Krueger, A.B. Disruptive Change in the Taxi Business: The Case of Uber. American Economic Review 106, 5 (2016), 177-182.

[13] Cusumano, M.A. How traditional firms must compete in the sharing economy. Communications of the ACM 58, 1 (2014), 32-34.

[14] Danaher, B., Dhanasobhon, S., Smith, M.D., and Telang, R. Converting Pirates Without Cannibalizing Purchasers: The Impact of Digital Distribution on Physical Sales and Internet Piracy. Marketing Science 29, 6 (2010), 1138-1151. 
[15] Davis, F.D. Perceived Usefulness, Perceived Ease of Use, and User Acceptance of Information Technology. MIS Quarterly 13, 3 (1989), 319.

[16] Dion, K.L., Baron, R.S., and Miller, N. Why do Groups Make Riskier Decisions Than Individuals? Advances in Experimental Social Psychology 5, (1970), 305-377. [17] Eliashberg, J. and Winkler, R.L. Risk Sharing and Group Decision Making. Management Science 27, 11 (1981), 1221-1235.

[18] FiveThirtyEight. Uber Is Taking Millions Of Manhattan Rides Away From Taxis. 2015.

[19] Frechette, G.R., Lizzeri, A., and Salz, T. Frictions in a Competitive, Regulated Market Evidence from Taxis. SSRN Electronic Journal, (2015).

[20] Gardner, M. and Steinberg, L. Peer influence on risk taking, risk preference, and risky decision making in adolescence and adulthood: An experimental study. Developmental Psychology 41, 4 (2005), 625-635. [21] Ghose, A., Smith, M.D., and Telang, R. Internet exchanges for used books: An empirical analysis of product cannibalization and welfare impact. Information Systems Research 17, 1 (2006), 3-19.

[22] Greenwood, B.N. and Wattal, S. Show Me the Way to Go Home: An Empirical Investigation of Ride-Sharing and Alcohol Related Motor Vehicle Fatalities. MIS Quarterly 41, 1 (2017), 163-187.

[23] Hanks, R.D., Cross, R.G., and Noland, R.P. Discounting in the Hotel Industry: A New Approach. Cornell Hotel and Restaurant Administration Quarterly 33, 1 (1992), 15-23. [24] Huang, L.Y. and Hsieh, Y.J. Consumer electronics acceptance based on innovation attributes and switching costs: The case of e-book readers. Electronic Commerce Research and Applications 11, 3 (2012), 218-228.

[25] Keaveney, S.M. and Parthasarathy, M. Customer Switching Behavior in Online Services: An Exploratory Study of the Role of Selected Attitudinal, Behavioral, and Demographic Factors. Journal of the Academy of Marketing Science 29, 4 (2001), 374-390.

[26] Kerr, N.L., MacCoun, R.J., and Kramer, G.P. Bias in judgment: Comparing individuals and groups. Psychological Review 103, 4 (1996), 687-719.

[27] Kuruzovich, J., Viswanathan, S., Agarwal, R., Gosain, S., and Weitzman, S. Marketspace or Marketplace? Online Information Search and Channel Outcomes in Auto Retailing. Information Systems Research 19, 2 (2008), 182 201.

[28] Lahiri, K. and Schmidt, P. On the Estimation of Triangular Structural Systems. Econometrica 46, 5 (1978), 1217.

[29] Lee, K., Lee, B., and Oh, W. Thumbs Up, Sales Up? The Contingent Effect of Facebook Likes on Sales Performance in Social Commerce. Journal of Management Information Systems 32, 4 (2016), 109-143.

[30] Li, Z., Hong, Y., and ZHang, Z. An Empirical Analysis of On-Demand Ride Sharing and Traffic Congestion. ICIS 2016 Proceedings, (2016).

[31] Luo, X. How Does Shopping With Others Influence Impulsive Purchasing? Journal of Consumer Psychology 15, 4 (2005), 288-294.

[32] Lynn, M. Tipping in Restaurants and Around the Globe: An Interdisciplinary Review. Handbook of Contemporary
Behavioral Economics: Foundations and Development, (2006), 626-643.

[33] Malhotra, A. and Van Alstyne, M. The dark side of the sharing economy .... and how to lighten it. Communications of the ACM 57, 11 (2014), 24-27.

[34] Meyer, J. Uber-Positive: Ride-Share Firm Expands Transportation Options in Low-Income New York. Manhattan Institute for Policy Research, 2015.

[35] Mohammed, R. Uber's New Tipping Policy Is a Mistake. Harvard Business Review, (2016).

[36] New York Post. More Uber cars than yellow taxis on the road in NYC. 2015. http://nypost.com/2015/03/17/moreuber-cars-than-yellow-taxis-on-the-road-in-nyc/. [37] PwC. The Sharing Economy - Sizing the Revenue Opportunity. PricewaterhouseCoopers, 2014.

[38] Rawls, J. A theroy of justice. Harvard University Press, Cambridge, Massachusetts, 1971.

[39] Rayle, L., Shaheen, S., Chan, N., Dai, D., and Cervero, R. App-Based, On-Demand Ride Services: Comparing Taxi and Ridesourcing Trips and User Characteristics in San Francisco. University of California Transportation Center Working Paper, (2014).

[40] Rogers, E. Diffusion of Innovations. Simon and Schuster, 1962.

[41] Sarker, S., Valacich, J.S., and Sarker, S. Technology Adoption by Groups: A Valence Perspective. Journal of the Association for Information Systems 6, 2 (2005), 37-71. [42] Smart, R., Rowe, B., Hawken, A., et al. Faster and Cheaper: How Ride-Sourcing Fills a Gap in Low-Income Los Angeles Neighborhoods. BOTEC Analysis Corporation, 2015.

[43] Smith, M.D. and Telang, R. Competing with free: The impact of movie broadcasts on DVD sales and Internet piracy. MIS Quarterly 33, 2 (2009), 321-338.

[44] Stoner, J.A.F. A Comparison of Individual and Group Decisions Involving Risk. 1961.

[45] The Economist. A Tale of Two Cities. The Economist, 2015. http://www.economist.com/news/united-

states/21661016-does-uber-substitute-cabs-or-attract-newriders-it-depends-where-you-live-tale.

[46] Vannoy, S. a. and Palvia, P. The social influence model of technology adoption. Communications of the ACM 53, 6 (2010), 149.

[47] Wallach, M. a, Kogan, N., and Bem, D.J. Group influence on individual risk taking. Journal of Abnormal and Social Psychology 65, 2 (1962), 75-86.

[48] Wallsten, S. The Competitive Effects of the Sharing Economy: How is Uber Changing Taxis? Technological Policy Institute, 2015.

[49] Zengyan, C., Yinping, Y., and Lim, J. Cyber migration: An empirical investigation on factors that affect users? Switch intentions in social networking sites. HICSS 2009 Proceedings, (2009), 1-11.

[50] Zervas, G., Proserpio, D., and Byers, J. The rise of the sharing economy: Estimating the impact of Airbnb on the hotel industry. Journal of Marketing Research, forthcoming (2017). 